\title{
Bilingual experiences with intercultural approach, in the higher normal school of Valladolid, Yucatán; Mexico." Study plan 2012
}

DOI: $10.46932 / \mathrm{sfjdv2n2-072}$

Received in: March 1st, 2021

Accepted in: May 30th, 2021

\section{Ramos Martín Silva Castro}

Postdoc.

INSTITUTION: Higher Normal School "Juan de Dios Rodríguez Heredia" Valladolid, Yucatán, México.

\section{Landy Aracelly Loeza Rosado $\mathrm{PhD}$.}

INSTITUTION: Higher Normal School "Juan de Dios Rodríguez Heredia" Valladolid, Yucatán, México.

\section{Yara Ivone Villanueva Azcorra}

MEd.

INSTITUTION: Higher Normal School "Juan de Dios Rodríguez Heredia" Valladolid, Yucatán, México.

\section{Jorge Alfredo Tec Jiménez}

BA.

INSTITUTION: Higher Normal School "Juan de Dios Rodríguez Heredia" Valladolid, Yucatán, México.

\section{Luis Fernando Che Dzib}

MEd.

INSTITUTION: Higher Normal School "Juan de Dios Rodríguez Heredia" Valladolid, Yucatán, México.

\section{Luis Enrique Ramos Domínguez \\ MEd.}

INSTITUTION: Higher Normal School "Juan de Dios Rodríguez Heredia" Valladolid, Yucatán, México.

\section{RESUME}

According to the National Institute of Statistics, Geography and Informatics in Mexico (INEGI, 2010) about 800,000 people over 5 years of age are Mayan speakers in Yucatán, where 538,355 are reported. According to Pineda, cited by Krotz (2008), Valladolid is one of the municipalities in the state with the largest number of Mayan speakers.

Since the 2004 curriculum, the Intercultural Bilingual Primary Education Bachelor's Degree (LEPIB in Spanish), serves this population since our students carry out their teaching practices and provide their professional services with children from the municipality, approximately $50 \%$ of whom are Mayan speakers in their entirety.

Since 2005, the "Juan de Dios Rodríguez Heredia" Higher Normal School has been responsible for teaching the LEPIB, being this school the only one in the state with this degree. 
Due to the characteristics of the incoming students, most of whom do not speak the Mayan language, several actions have been implemented for the teaching of this language in correspondence with the graduate profile of the 2012 curriculum.

The reform of the 2012 curriculum includes bilingual intercultural teaching competencies, which emphasizes the acquisition of linguistic skills of the native language, in this case, the Mayan language.

Keywords: Study plan 2012, Intercultural teaching competencies, Intercultural approach, Mayan language.

\section{CONTENT}

\subsection{PROBLEM STATEMENT}

Given that the "Juan de Dios Rodríguez Heredia" Higher Normal School is located in a region where the Mayan language is alive, despite the historical efforts made to disappear it, today it is more alive than ever, so at the time it changed the 1997 plan for the 2004 plan whose characteristic of the latter is the intercultural bilingual approach in its eagerness to offer society, teachers who meet the current requirements in intercultural bilingual education, faced significant challenges, such as the lack of the requirement of the Mayan language for the profile of entry to the school, monolingual students are accepted in Spanish, but in teaching practices, require teachers according to the program of the Bachelor of Intercultural Bilingual Primary Education, 2004, contribute to the modification of the ways to address the cultural diversity of schools, to improve relations between subjects and to strengthen the curricula, the organization of teaching, teaching activities in the classroom and institutional management. At the same time, it fosters dynamic and interdisciplinary participatory pedagogical processes that help link the sociocultural and linguistic reality of the students with the school and the school with the community. It is expected that future teachers will have the capacity to include and articulate as a pedagogical resource the diversity present in the classroom so that the higher normal school will promote the experience and recreation of the principles of interculturality such as knowledge of diversity, respect for differences, recognition, and appreciation of other identities and the willingness to coexist with other cultural styles.

Thus, this study is intended to be carried out because the levels of proficiency in the Mayan language of the 289 students of our institution are unknown.

In addition to the above, the geographical situation of this place contemplates neighboring populations with multigrade schools and even in the outskirts of the same city. On the other hand, in research of this institution on the follow-up of graduates, it has also been reflected the weakness in their intercultural teaching skills. Therefore, the following problem is posed: 
How to favor the acquisition of a second language in monolingual students in Spanish and strengthen their cultural identity?

\section{THEORETICAL FRAMEWORK}

The second article of the Constitution of the United Mexican States "recognizes the pluricultural composition of the Mexican nation originally sustained in its indigenous peoples and guarantees the right of said peoples to preserve and enrich their culture, language, knowledge and values, and it is the government's obligation to establish social policies and institutions oriented towards the peoples and communities to achieve equal opportunities, the elimination of discriminatory practices, as well as their integral development, through the active participation of the "indigenous peoples" themselves, Furthermore, the general law on the linguistic rights of indigenous peoples establishes the norms for a linguistic policy that encourages the strengthening and development of the native languages of Mexico" so that the "future teacher must reverse the effects of social inequality and discrimination" by incorporating the study and reflection on his or her own socio-cultural and linguistic conditions.

According to INALI (2008), the linguistic variation of the Mayan language spoken in three states (Yucatan, Campeche, and Quintana Roo) is not significant, so it can be said to be the same language.

The inclusion of the intercultural approach was given in a cross-cutting manner from the programs of the 1997 Plan of the Bachelor's Degree in Elementary Education to the current 2012 plan of the LEPIB, as well as the constitution of a formative path called Languages and Cultures of the Original Peoples.

According to Salmerón (2010) the purposes of the Bachelor's Degree in Intercultural Primary Education are, among others:

Reverse the effects of inequality and social discrimination.

- To promote fundamental changes in the mentality of the various educational actors, particularly future teachers.

- To promote participatory, dynamic, and interdisciplinary pedagogical processes that help to link the socio-cultural and linguistic reality of the students with the school and the school with the community.

Likewise, it must be taken into account that the intercultural teaching competencies that the graduates of this degree must have are:

a) The mastery of the indigenous language.

b) Recognition and appreciation of the knowledge, wisdom, values historically and culturally constructed by indigenous peoples and communities.

c) Knowledge of the characteristics and structure of indigenous languages.

d) Understanding of the processes involved in the teaching and learning of a second language. 
e) Didactic competence.

f) Competencies for study and lifelong learning in general and specific training.

Because of this, the need to acquire the learning of the Mayan language, in the future teachers, is circumscribed within the framework of culture and language, as well as to accept the value it has to use it and later, to teach using the native language as a means of instruction, communication and as an object of study in an adequate manner in the attention to diversity.

We have defined as precisely as possible the traits of the elementary school teacher who attends to sociocultural, linguistic, and ethnic diversity from the intercultural bilingual approach that Mexico requires.

These traits will respond not only to the needs of knowledge and professional competence posed by the application of the elementary school curriculum but also to the attitudes and values that characterize educators in the broader sphere of their relationships with children, families, and the socio-cultural environment of the school.

It also considers the skills that enable lifelong learning, such as the systematic study of the teaching experience, its analysis, and reflection, which must be present in all graduates of teacher training institutions. Official Gazette (2009).

The 2012 plan contemplates within the graduate profile the intercultural bilingual teaching competencies, which indicate that it should be a means of teaching, knowledge and as an object of study, are articulated in a set of paths and courses aimed at achieving the graduate profile of the future teacher of the Bachelor's Degree in Intercultural Bilingual Primary Education, which integrate the curriculum. Teachers when working in contexts of socio-cultural and linguistic contrasts must have bilingual intercultural teaching competencies, based on the fundamentals of pedagogical processes and communicative skills, as well as on the analysis and diagnosis of the cultural and linguistic reality, particularly focused on native peoples. These competencies constitute, together with the generic and professional competencies, the graduate profile.

Intercultural competence is one of the competencies that a language teacher must have to teach and transmit. The future teacher must develop knowledge and competencies that allow him/her to know the type of bilingualism with which students begin their schooling. Teacher training is considered a process that takes place in different times and spaces through which a way of reflecting and acting in the teaching profession is acquired. 
On the other hand, in the new reform plan from 2012, actions that support students to develop linguistic and metalinguistic skills during their professional practices are pertinent for the achievement of the graduate profile.

\section{METHODOLOGY}

Since 2005, the "Juan de Dios Rodríguez Heredia" Higher Normal School has been responsible for teaching the Bachelor's Degree in Elementary Education with a Bilingual Intercultural Approach. Due to the characteristics of the students who enter the school, seven Mayan language courses have been designed for three and a half years: Initial Mayan (level 1 and 2), Intermediate Mayan (level 1 and 2), Advanced Mayan (level 1 and 2) and a reinforcement course for the last grade that support the productions of the courses of the subjects of the specific form for the educational attention to the cultural, linguistic and ethnic diversity (language and culture 1,2 and 3, bilingual processes, workshop of design of didactic proposals, etc. ) and the elaboration of the degree work.

To diagnose the level of mastery of the Mayan language, the instrument designed by the Universidad de Oriente was used, which consists, according to Cortés, (2010):

In a software that allows management of text, images, and voice, as well as the automatic scoring of the items corresponding to reading comprehension, listening comprehension, and the first three levels of written expression competence. Most of the items of this instrument are multiple-choice, except for levels four and five of the written proficiency and all levels of oral proficiency.

The table of specifications recommended by the experts determined the minimum number of items per level. It was elaborated to discard those that were not appropriate, after the pilot test; however, what was done was to reformulate them and keep the number with which it was elaborated, to have a greater opportunity to test the level of competence.

Table 1. Levels of proficiency in the Mayan language.

\begin{tabular}{|l|l|l|l|l|l|}
\hline \multicolumn{2}{|l|}{ Elementary level $(0-30 \%)$} & \multicolumn{1}{l}{ Intermediate level (30/60\%) } & \multicolumn{2}{l|}{ Advanced level (60/100\%) } \\
\hline A1 $(0-10 \%)$ & A2 $(10-30 \%)$ & B1 $(30-40 \%)$ & B2 (40-60\%) & C1 (60-80\%) & C2 (80-100\%) \\
\hline
\end{tabular}




\begin{tabular}{|c|c|c|c|c|c|}
\hline $\begin{array}{l}\text { The student is } \\
\text { able to } \\
\text { understand and } \\
\text { use frequently } \\
\text { used everyday } \\
\text { expressions: } \\
\text { simple } \\
\text { sentences to } \\
\text { satisfy } \\
\text { immediate } \\
\text { needs, can } \\
\text { introduce } \\
\text { him/herself and } \\
\text { others, in L2, } \\
\text { can ask } \\
\text { everyday } \\
\text { questions to } \\
\text { gather } \\
\text { information. }\end{array}$ & $\begin{array}{l}\text { Can understand } \\
\text { sentences and } \\
\text { frequently used } \\
\text { expressions } \\
\text { related to areas of } \\
\text { experience that } \\
\text { are particularly } \\
\text { relevant to } \\
\text { him/her (basic } \\
\text { information about } \\
\text { him/herself and } \\
\text { his/her family, } \\
\text { occupations, } \\
\text { domestic animals, } \\
\text { wild animals, use } \\
\text { of pronouns...) } \\
\text { Can communicate } \\
\text { in a basic way } \\
\text { when carrying out } \\
\text { simple tasks. }\end{array}$ & $\begin{array}{l}\text { Understand the } \\
\text { main points in clear } \\
\text { texts if they deal } \\
\text { with familiar topics } \\
\text { (stories, legends, } \\
\text { myths, national } \\
\text { anthem...). } \\
\text { Whether in work, } \\
\text { study or leisure } \\
\text { situations (everyday } \\
\text { use). } \\
\text { Can deal with most } \\
\text { situations likely to } \\
\text { arise whilst } \\
\text { travelling in an area } \\
\text { where the language } \\
\text { is spoken, can } \\
\text { produce simple, } \\
\text { coherent texts on } \\
\text { topics which are } \\
\text { familiar or of } \\
\text { personal interest to } \\
\text { him/her. }\end{array}$ & $\begin{array}{l}\text { Can understand } \\
\text { the main ideas of } \\
\text { texts dealing with } \\
\text { complex and } \\
\text { abstract subjects, } \\
\text { provided they are } \\
\text { in his/her field of } \\
\text { specialization. } \\
\text { Can interact with } \\
\text { native speakers } \\
\text { with a sufficient } \\
\text { degree of fluency } \\
\text { and spontaneity. } \\
\text { Can produce clear } \\
\text { texts according to } \\
\text { the learner's topic } \\
\text { or interest. } \\
\text { (applies } \\
\text { interviews in } \\
\text { Mayan language, } \\
\text { understands } \\
\text { conversations). }\end{array}$ & $\begin{array}{l}\text { Communication } \\
\text { level almost like } \\
\text { a native speaker, } \\
\text { able to function } \\
\text { in a professional } \\
\text { environment. } \\
\text { Is able to } \\
\text { understand a } \\
\text { wide variety of } \\
\text { texts and with a } \\
\text { certain level of } \\
\text { demand, as well } \\
\text { as recognize } \\
\text { implicit } \\
\text { meanings in } \\
\text { them. } \\
\text { Shows the } \\
\text { correct use of } \\
\text { the mechanisms } \\
\text { of organization, } \\
\text { articulation and } \\
\text { cohesion of the } \\
\text { text. }\end{array}$ & $\begin{array}{l}\text { Understands } \\
\text { everything } \\
\text { he/she hears or } \\
\text { reads, just like a } \\
\text { native speaker, } \\
\text { creates } \\
\text { arguments in a } \\
\text { coherent and } \\
\text { summarized } \\
\text { manner, } \\
\text { produces texts } \\
\text { that do not } \\
\text { require revision } \\
\text { by the teacher, } \\
\text { the student } \\
\text { reaches a level } \\
\text { of certification } \\
\text { of a second } \\
\text { language (L2). }\end{array}$ \\
\hline
\end{tabular}

Note: Mayan language proficiency levels according to the Common European Framework.

The data were analyzed using descriptive statistics, with the support of SPSS software (Statistical Package for the Social Sciences), through which we obtained the overall score, by grades, levels, competencies, students and gender, which gave us elements to make various inferences and conclusions that will help us to implement various actions that favor the acquisition of mastery of the Mayan language by our students.

\section{DEVELOPMENT AND DISCUSSION}

In the 2012 curricula, a series of activities were contemplated in different subjects that require the construction of bilingual texts (Mayan-Spanish), which assumes that students have certain linguistic skills in Mayan, which are lacking in most cases, since of all students entering the higher normal school, only some speak the Mayan language but do not write it, and the rest lack this ability. On the other hand, it has always been a challenge for the institution to train bilingual students.

Currently, and under the current curricula, the following actions are being carried out:

a) The Mayan language workshop, which is taught with two hours per week on a mandatory basis from the first to the fifth semester, manages three levels based on the Common European Framework for teaching the different languages of the world: the first level "initial" with a command of zero to thirty percent of the language, subdivided into level A1 as initial and A2 as initially advanced initial, the intermediate level includes a command of the language from thirty percent to sixty percent, divided into B1 initial intermediate and B2 advanced-intermediate, finally the advanced level with a command of the 
language from sixty to one hundred percent: divided into $\mathrm{C} 1$ advanced intermediate and $\mathrm{C} 2$ advanced level.

b) Two elective courses were designed by teachers of the institution to teach the Mayan language I and II which was approved by the Directorate of Higher Education and the DGESPE to be taught as an elective course in the 6th and 7th grades. AND $7^{\circ}$. Semester of the curriculum of the 2012 Study Plan.

c) The learning route was prepared concerning the language, corresponding to the activities of the Formative Path of Languages and Cultures of the Native Peoples, which includes the following subjects and which is being followed up on regularly:

FIRST SEMESTER. Cultural and linguistic diversity in Mexico and interculturality. Nodal points, projects for the inclusion of the language, programs for the inclusion of the language and culture are constructed, observation and interview guides are elaborated and a format of tools for communication is elaborated. (Vocabulary of phrases related to the school).

SECOND SEMESTER. Intercultural and linguistic processes in education. Mayan sentences are elaborated. The topics of social bilingualism (context) and bilingualism in education (school) are worked on. Didactics of the language (inductive, comparative, direct methods, sounds, etc.) Didactic sequences are elaborated through linkage with the subject of primary education.

THIRD SEMESTER. Native languages as an object of study I.

The levels of the language, phonetics (sounds), phonology (words), minimum pairs (data, bata) Spanish (Miis/gato, Míis/barrer; Páak /Tomate, Paak/pegar) are also worked on.

FOURTH SEMESTER. Native languages as an object of study II

We work on morphology (word order), semantics (word order-sentence), syntax (sentence structure), and pragmatics (sentence production). A text is proposed (the five linguistic skills are completed).

FIFTH SEMESTER. Native languages and their pedagogical intervention. Psycholinguistic and sociolinguistic diagnoses are applied (parents) (classroom). Through community knowledge as language strategies (taxonomic classification) (semantic fields, knowledge construction, object of study), theories are created, planning projects, and didactic sequences are elaborated. 
SIXTH SEMESTER. Educational research applied to native languages and cultures. The starting point is a plan of action of a detected plan from which a general idea is proposed. It is based on the structuring of an action plan according to the theoretical and methodological approach of action research and its implementation related to languages and cultures.

SEVENTH SEMESTER. The research applied to pedagogical research in intercultural contexts. They elaborate a proposal of pedagogical intervention relevant to the context of linguistic and cultural diversity.

d) A project of "internal tutors" is developed among peers, whose objective is to reinforce and promote the Mayan language during classes, through different activities that are carried out permanently, in the courses of the formative path of languages and culture of the native peoples and the Mayan language workshops during the semesters. (1st to 7 th semesters). The actions that are carried out in this regard are a) to support the classes during the activities that are developed in the courses and to accompany their monolingual companions in Spanish. b) During the observation and assistantship days, to support in the use of the Mayan language (as a means of communication), to strengthen and support in its translation, c) In the use of the Mayan language and its writing, during the different cultural events that are experienced or carried out, through the realization of (ethnographic reports and video editions), d) In the observation visits and teaching practices (Vaquerías, guilds, hanal pixan, jeests“mek, looj, etc.) f) To guide in the elaboration of research tools (revision of formats of communication tools (Mayan phrases), lesson plans (Mayan), ethnographic reports in the Mayan language. Interview guides in Mayan-Spanish.

\section{RESULTS}

Results for the 2017-2018 school year in terms of Mayan language proficiency concerning the Common European Framework.

\begin{tabular}{|c|c|c|c|c|c|c|}
\hline & \multicolumn{2}{|c|}{ inicial (0/30\%) } & \multicolumn{2}{|c|}{ intermedio (30/60\%) } & \multicolumn{2}{|c|}{ avanzado (60/100\%) } \\
\hline & A1 (0-10\%) & A2 (10-30\%) & B1 (30-40\%) & B2 (40-60\%) & C1 (60-80\%) & C2 (80-100\%) \\
\hline $1^{\circ}$ & 9 & 16 & 22 & 22 & & \\
\hline $2^{\circ}$ & 37 & 9 & 6 & 8 & & \\
\hline $3^{\circ}$ & & 18 & 18 & 18 & 18 & 18 \\
\hline $4^{\circ}$ & & 14 & 14 & 14 & 14 & 14 \\
\hline TOTAL: & 46 & 57 & 60 & 62 & 32 & 32 \\
\hline & TOTAL DE & ALUMNOS: & 289 & & & \\
\hline
\end{tabular}




\section{Niveles de dominio}

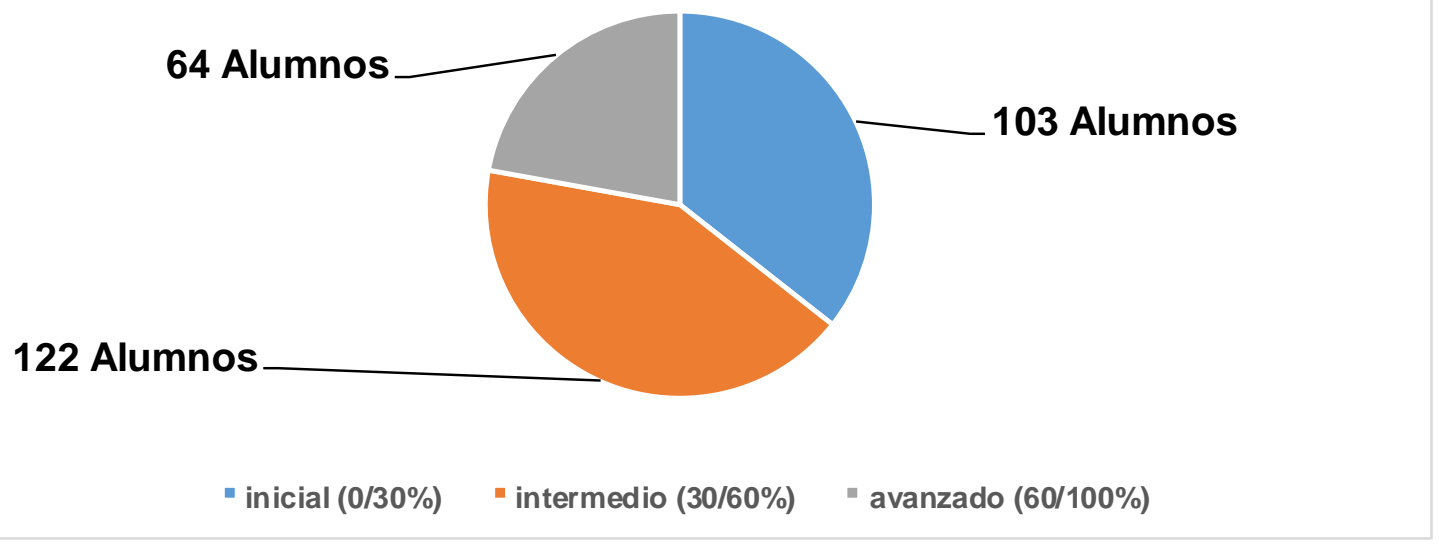

According to the table and graph presented:

a) Only $16 \%$ (46) 1st and 2nd-grade students are currently in A1.

b) $20 \%$ (57) students are in A2 which is the minimum desirable.

c) $64 \%$ (186) is between B1 and C2, which exceeds the minimum desirable.

d) $80 \%$ (56) of the students in the 4th. d) $80 \%$ (56) of the students in the 4th grade are between B1 and C2 and only $20 \%$ (14) are in the minimum desirable.

e) $100 \%$ of the students in the $3 \mathrm{rd}$ and 4 th. e) $100 \%$ of the $3 \mathrm{rd}$ and 4 th-grade students have reached the minimum desirable level (A2).

In terms of achievements, the following can be noted:

- In previous years, the institution has supported the updating of teachers in different courses and diploma courses in the Mayan language, given by external organizations.

- A diagnostic test is applied to applicants to the Intercultural Bilingual Elementary Bachelors Degree of the Escuela Normal "Juan de Dios Rodríguez" of Valladolid, Yucatán, Mexico to know their level of proficiency in the Mayan language.

- At the end of the last school year (2016-2017) three teachers and twenty students from the different groups (second semester, fourth and sixth) were certified in the Mayan Language. The certification was carried out by the Universidad de Oriente with resources from ProFEN.

- Undoubtedly, one of the most important achievements was the development of two Mayan language courses, which, due to their relevance, the Directorate of Higher Education approved their implementation as an elective course endorsed by the DGESPE (Directorate of Higher Education for Education Professionals). 
- In the 2016-2017 school year, one student completed his degree work in the modality of the research thesis, written and disserted in the Mayan Language.

\section{CONCLUSIONS}

From the experiences contemplated in this work, we conclude the following:

- It is important to ensure that teacher training students understand and carry out their planning in a pertinent manner during their teaching practice from an intercultural perspective, given the contexts of the schools where they are assigned.

- It is transcendental that teacher training students master the basic principles of intercultural bilingual education and assess how it contributes to the achievement of the goals of education with quality, equity, and relevance.

- It is a priority to attend to the teaching of the Mayan language for the acquisition of the corresponding linguistic skills for optimal performance in the professional practices that the students carry out and for their professional life.

- It is necessary to have teachers who are fluent in the native language where the Intercultural Bilingual Bachelor's Degree is taught. 


\section{REFERENCES}

Cortés, C.G. (2010) ¿Educación Bilingüe en Lengua Maya?, México D.F.

Krotz, E. (2008) Yucatán ante la ley general de derechos lingüísticos de los pueblos indígenas.

INALI. (2008). Ley general de derechos lingüísticos de los pueblos indígenas, México, D.F.

INEGI (2010) www.inegi.org.mx. Recuperado el 30 de enero de 2019

SEP, (1997) Plan de Estudios 1997. Licenciatura en Educación Primaria, México, D.F.

SEP, (2004) Plan de estudios 2004. Licenciatura en educación primaria intercultural bilingüe, México, D.F.

SEP, (2012) Acuerdo 651, Plan de Estudios para la formación de Maestros de Educación Primaria Intercultural Bilingüe, México D.F. 